\title{
You Were Right About Paris Stephen Nichols
}

I imagined going to Disneyland, Vegas and the Grand Canyon then Route 66 to Chicago home of the Blues Brothers

Your heart was always set on Paris seeing the Eiffel Tower holding hands along the Champs-Élysées

The Seine is beautiful in late autumn, the leaves of the Linden trees along its bank rust and fall into the water

Sure-there are no stairs in my hotel but there is Monet in every window and you can smell the coffee from the café below

You were right about Paris You were right about a lot of things You were wrong about me 